\title{
LA IDEA DEL ORDEN JURIDICO EN LOS PRIMEROS CONTRARREVOLUCIONARIOS FRANCESES ${ }^{1}$
}

\author{
CRIstian Garay Vera \\ Magister en Historia
}

SUMARIO.- - I. Introducción. II. El orden político: 1. Los fundamentos sobrenaturales: 1.1. El orden teológico como paradigma. 12. El orden físico y el orden humano. 2. Naturaleza del orden político. III. La nación: 1. La tradición, constitución histórica: 1.1. La filosofía como falsa Constitución. 2. Religión, moral y ley: 2.1 . Religión. 2.2. Moral. 2.3. Ley. IV. La monarquía consagrada.

\section{INTRODUCCION}

Pocas noticias existen respecto de las concepciones jurídicas de los primeros contrarrevolucionarios franceses, en especial cuando se comprueba la ignorancia generalizada de esta corriente en sus inicios y su común adscripción al Tradicionalismo Filosófico y al Ro manticismo, desvirtuando algunos rasgos propios, diversos $\rightarrow$ por ejemplo- del tradicionalismo alemán.

En efecto, tal como en el exterior, 1796 es el año clave de la floración $\mathrm{y}$ estructuración de un movimiento que venía desde antes. Por un lado, en el exterior, se sucederán en ese año o posteriormente las obras del irlandés Burke, del suizo Mallet du Pan, del alemán Haller y, en cierto modo, del saboyano De Maistre. Por el otro, cristalizará la crítica temprana sostenida por De Rivarol en su periódico y del pensamiento de Saint-Martin (1743-1803), quien se ha. cía llamar el "Robinson de la espiritualidad" y que representó el

1 Este trabajo corresponde a un trabajo complementario del artículo publicado en revista "Academia" (Santiago) No 18 (1989), denominado De Maistre y la revolución francesa, y cuyo sentido era precisar las ideas más pertinentes al orden institucional sustentadas en su obra Estudio sobre la soberania, escrita entre 1794 y 1796 e inédito hasta 1870 y cuya sola traducción al castellano se encuentra en la edición de Editorial Dictio, Buenos Aires, 1978. 
rechazo al racionalismo. Ese año, 1796, este último pública su Eclair sur l'association humaine que resumió las ideas contenidas en sus propias. Considérations sur la révolution française de un año antes.

La posición de Saint-Martin fue, a su vez, la primera que destacó el misticismo y la impotencia de la razón, y por ello Louis Delbez en su Les grands courants de la pensée politique française depuis le XIX siècle (1970) ha subrayado que su obra fue la génesis de cuantas vinieron con posterioridad.

A su vez, Antoine de Rivarol ${ }^{2}$ reivindicó el honor de haber criticado primeramente la Revolución Francesa, cerca de 1790 , en su Diario Político Nacional, publicación fundada para combatir ese hecho político.

Un lugar privilegiado tiene el conde Joseph de Maistre, 3 quien por el hecho de ser un saboyano francófilo, compartió la génesis de ambas escuelas contrarrevolucionarias, la externa e interna, desde su puesto de cortesano del rey de Cerdeña. Tuvo por lo demás seguidores en Francia como Adolphe-Antoine Blanc du Saint Bonnet.4 Esta escuela tuvo, además, otro representante: Louis-Ambroise de Bonald, Vizconde de Bonald, ${ }^{5}$ quien intentó fundamentar filosó-

2 Antoine de Rivarol, que recibió posteriormente el título de Conde de Rivarol y la dignidad de Caballero, escritor francés de origen piamontés, nació en 1753 y falleció en 1801. Su obra principal radica en los escritos periodísticos con que combatió el proceso, y en sus cartas, entre ellas La carta a la nobleza francesa, donde pide la magnanimidad de ese estamento si vuelve al poder en Francia. Fue partidario de una salida populista del Rey para aplastar la Fronda.

3 Joseph de Maistre, noble piamontés, nació en 1753 y murió en 1821. Durante su vida fue embajador del Reino del Piamonte. Residió hacia 1789 en Francia y al momento de los acontecimientos re volucionarios emigró a Turín, desde donde empezó a escribir sus primeras obras, de la cual la más famosa Considérations sur France. En 1799 ejerció de embajador en Rusia y en 1803 fue honrado con el título de Conde.

- Publicista francés, nacido en 1815 y muerto en 1880. Autor de Politica real, donde defiende la necesidad de la religión para el orden político y social.

5 Miembro de la nobleza, nació en 1754 y murió en 1830 . Durante su existencia adhirió firmemente a la monarquía, lo que le valió el exilio en 1791. Se alistó en el "Ejército de los Príncipes" y se estableció en la ciudad de Heidelberg. En 1796 escribió su Teoría del poder político y religioso, donde establece las principales ideas por las cuales es nombrado Ministro de Instrucción Pública en la Restauración y diputado (1815-1822). 
ficamente la teoría política contrarrevolucionaria, principalmente desde la teoría del lenguaje y de la sociedad, para así arribar a la demostración racional de la impronta sobrenatural del orden creado, del cual era parte el orden humano.

Estos autores, entre otros comb Brehier, Saint-Martin, Ballanche, tienen en común la defensa de una monarquía religiosa dentro de la defensa de la tradición como doble expresión de un orden divino anterior a la voluntad del legislador y de una experiencia histórica beneficiosa. De esta última premisa se explica, pues, la monarquía como constitución histórica y no escrita, precedente a toda ley, fundamentada en la costumbre y la religión, que es lo que les interesó sostener.

No hubo en estos autores conciliación alguna con el liberalismo, ni siquiera en su aspecto más mitigado como apareció en Burke, que influyó tanto a su vez en la traducción de F. von Gentz en 1798, en el nacimiento del romanticismo alemán, 6 escuela con la que se suele identificar sin más.

Su postura aparece como expresión del partido ultra que estará detrás de la Restauración postnapoleónica, de una fase de la Santa Alianza y del reinado de Carlos X. Sin embargo, el propósito de estos "reaccionarios" al liberalismo no fue el de la simple restauración, tal como lo había dejado establecido ya en 1796 De Maistre en sus Considérations, cuando estableció que su contrarrevolución era diversa de la República y la monarquía anterior.

Su inspiración provino de la respuesta católica a la Ilustración y el Racionalismo que habían minado la influencia de la Iglesia $\mathrm{Ca}$ tólica en la vida de Francia y de Europa. Fue en este sentido que la teoría política de estos autores se configuró para reafirmar tanto la autoridad monárquica como para defender el magisterio de la Iglesia Católica.

La teoría que subyace bajo sus argumentaciones no es escolástica o tomista, sino que entronca con la teoría de los sentidos, con las tesis agustinianas y platónicas que están, por ejemplo, en el centro de la brillante exposición de $\mathrm{De}$ Bonald ${ }^{7}$ y que expresa reitera. damente su reticencia al individualismo y el racionalismo.

- Respecto de su carácter es preciso consultar Carl Schmitt, Romantisme Politique; Ernst Benz, Les sources mystiques de la phi. losophie romantique allemande, y Auguste Viatte, Les sources occultes du romantisme, illuminisme-théosophie 1770-1820.

7 Palacios ha dejado sobradamente establecido que De Bonald asiente a esta filiación no sólo con Platón sino también con Descartes en el entendido que para él el peripatetismo degenerará en la fi- 
De esa misma matriz se generan también su concepción suprahistorica de la tradición; su teoría del conocimiento connatural; su negación de la accesibilidad de la Verdad objetiva por las solas fuerzas de la razón natural (dogma de fe); su desprecio por las tesis de la libertad humana y de su bondad connatural; y su aprecio por toda suerte de corrientes subjetivas y emotivas.

Todo ello hace que el sistema descanse sobre la convicción de una trasmisión -antes del pecado original- que alcanza al hombre antes de traspasarse a su nuevo estado, donde sólo la sociedad y la divinidad podrán traspasarles los elementos para su elevación. ${ }^{8}$

Asimismo, en auxilio de su lucha contra Rousseau, los tradicionalistas franceses extremaron sus posturas providencialistas y pesimistas. Contradiciéndole, sostuvieron que la persona era siempre instrumento inadvertido de la Providencia, tanto para premiar como para castigar a los pueblos, y con respecto a la naturaleza humana la consideraron irreparablemente dañada después del pecado original, relativizando el valor de la libertad, base de la exaltación del progreso ilustrado.

Igualmente, advirtieron que la naturaleza humana suponía el mal y que ésta era la categoría soslayada por el idealismo revolucionario. Como diría De Maistre en el Capítulo II de sus Considérations: "Il n'y a que violence dans l'univers; mais nous sommes gatés par la philosophie moderne, qui a dit que tout est bien, tandis que le mal a tout souillé, et que, dans un sens tres-vrais, tout est mal, puisque rien n'est a sa place".

Si nada está en su lugar es evidente que los autores han funda. do esa observación no sólo en el hecho circunstancial de un hecho político adverso como es la revolución, sino en su convicción que todo gobierno es en sí bueno y todo trastorno en él una desgracia.

losofía "inglesa" de Locke y de Condillac a la que atribuye la impronta revolucionaria. Ver El platonismo empirico de Luis de Bonald, pp. 4-5, en Revista de Estudios Políticos n. 74.

- El lenguaje es el signo de la creación "de .l'homme moral" para De Bonald. Por lo tanto, si el hombre recibe el lenguaje al tiempo de su existencia, si personalmente lo recibe de un ser superior "a lui en age et en connaissances", como género humano lo "a recu primitivement le langage d'un être antérieur a l'espece humaine et superieur a l'homme en intelligence", Recherches philosophiques, De Bonald, Oeuvres de M. de Bonald. Recherches..., 46.

9 Considérations sur la France, De Maistre, 43. "El mal -dice Blanc du Saint-Bonnet-, una única idea que lanza la práctica, os mata filosófica y políticamente, tampoco podéis despreciarla, por más que dependa de la Teología", Política real, p. 50. 
En palabras de De Maistre, todo gobierno es bueno y su sola ausencia es una forma de injusticia. Lo recuerda Schmitt cuando le cita en francés en su estudio Teología Politica: "tout gouvernement est bon lors qu'il est établi"10 y conviene en que el romanticismo que él le atribuye a estos autores ${ }^{11}$ se deshace ante su visión descarnada, que la ausencia de soberano es la que impone soluciones políticas más radicales.12

Ello tiene un profundo sentido ya que en "El Papa" el autor saboyano dirá que la justicia es una de las funciones del gobierno y que el gobierno surge a su vez de la necesidad de ordenar la sociedad. ${ }^{13}$ Por su parte, dado que la soberanía es el atributo del gobierno, la justicia es función del gobierno.

Ahora bien, aludiendo implícitamente a su tesis que es el individuo el que necesita a la sociedad y no al revés, y que es la sociedad la que necesita un soberano, De Maistre hará referencia a su pesimismo antropológico para fundar la necesariedad moral de la autoridad.

"El hombre - dirá De Maistre-, en su cualidad de ente a un mismo tiempo moral y corrompido, justo en su inteligencia y perverso en su voluntad, debe necesariamente ser gobernado, pues de otro modo sería a un tiempo mismo sociable e insociable, y la sociedad sería igualmente necesaria e imposible". ${ }^{14}$

10 Estudios politicos, Schmitt, 83.

11 Estudios..., Schmitt, 81.

12 Schmitt llega a identificar de tal modo el romanticismo con esta escuela que al hablar de De Bonald dice que se sorprende ante su perfil genuinamente alemán, ver Estudios..., 81. Por ello, es preciso tomar algunas distancias frente a su análisis, que en el fondo conviene más a Donoso Cortés y con errores extensivos tanto a los franceses como al español: Ya que no es el hecho desnudo de tomar la "decisión" política lo que les interesa, sino recuperar la legitimidad de la forma política imperante. No hay en ellos, pues, el anticipo que pretende Schmitt a la idea de la dictadura como soberanía excepcional continua, puesto que cuanto no hubiese sido esa fórmula de monarquía, que propugnaban, no era lo justo. Por ello, por lo demás, el Conde de Chambord rechazó dos veces el trono de Francia con posterioridad.

13 En una de las notas agrega: "No puede haber justicia sin sociedad, ni ésta subsistir sin un soberano que la dirija. La justicia supone ser entre diversas personas (pues es dar a cada uno su derecho): he aquí la sociedad; y alguno que haga aplicación de ellos: he aquí la soberanía", Del Papa, De Maistre, 185.

14 Del Papa, 186. 
Por ello los autores se vuelven en numerosas ocasiones llenos de reproches para condenar a Rousseau. De Rivarol lo calificó de "El más ardiente enemigo del orden político" cuya tesis sintetiza diciendo que el hombre es naturalmente "libre, justo y bueno".15 A su vez, Blanc du Saint-Bonnet sostuvo: "Es lo contrario de la proposición de Rousseau que hay que tomar: el hombre nace malo, y la sociedad lo reestablece. 0 más bien, nace en el mal, la Sociedad lo recoge y es la Iglesia la que lo repara".16

\section{EL ORDEN POLITICO}

\section{Los Fundamentos Sobrenaturales}

1.1. El orden teológico como paradigma del orden

El orden político, para los autores, no es más que una parte, todo lo predilecta que se quiera dada la condición privilegiada đel hombre según la Revelación, del orden de la Creación. Ello derivado de la adhesión a la teología católica que proclama al hombre como creatura predilecta a imagen y semejanza de su Creador. A la que añade su condición especialísima entre las creaturas vivientes de Hijo Adoptivo por el sacrificio de su Hijo Unigénito.

Es por tanto, un orden que tiene su causa eficiente, formal y final en Dios, y que recibe de Dios su sustento. Por ello la teología es la primera de las ciencias, puesto que al dar cuenta del inteligir creador resume en su génesis cuanto atañe al hombre creatura y creatura predilecta específicamente. "Al ver el universo y sus leyes - dirá De Rivarol-, se reconoce al eterno geómetra" en repetición casi exacta de las primeras líneas de las Consideraciones sobre Francia, de De Maistre, quien habla del "éternel géometre".17

Cuanto derive de ambos tendrá entonces sus propias características. Las obras del hombre serán débiles y precarias, como su propia naturaleza, las de Dios, ricas, fuertes y variadas, como corres-

15 "Sobre la filosofía moderna", De Rivarol, en Escritos Políticos 1789-1800, 534.

16 Politica.., Blanc du Saint-Bonnet, 57.

17 Sobre la..., De Rivarol, 489. El trabajo de De Rivarol, prefacio de un trabajo sobre la lengua francesa es de 1797, es decir, apenas un año después de las Considérations sur France de De Maistre: las similitudes son casi calcadas. 
ponde a su majestad. Cuanto cree Dios será ley fundamental, cuanto cree el hombre un remedo al que sólo su libertad -conjugada misteriosamente con la Providencia- da un viso de existencia.

El hombre conforme esta visión, expuesta por ejemplo en el segundo capítulo de las Considérations, de De Maistre, no podrá nunca crear algo con independencia del orden en que vive y de sus directrices fundamentales.

\subsection{El orden físico y el orden humano}

Pero una vèz que se reconoce que el orden natural es producto de la voluntad divina, es preciso completar la afirmación en el sentido lato de la naturaleza humana. Porque si el orden físico "castiga" las trasgresiones de sus leyes con efectos materiales evidentes (un cuerpo que desafíe la altura se rompe) el orden moral también debe hacerlo. Por ello la Providencia se sirve de la religión y de la moral como suplementos de la justicia rota por la concupiscencia y soberbia humana.

El deber del hombre, acota De Rivarol, es hacer que la perfección del orden físico o cósmico, se complete con la armonía del mundo moral y no se agravie la Inteligencia Infinita. "Si es preciso, para mantener el orden físico del mundo, que la naturaleza castigue los errores, la política debe, para mantener el orden social, castigar los crímenes conocidos, y servirse de la religión y de la moral para prevenir las pasiones y perseguir los crímenes ocultos en los refugios donde la ley no penetra".18

A juicio de los autores, la reposición del mundo moral concurre en parte importante por el Gobierno, en el sentido que éste restaura un cierto género de orden bueno en sí mismo. Como ya se ha dicho con anterioridad, la soberanía viene a ser a sus ojos la única posibilidad de hacer posible la sociedad dadas las condiciones actuales, malheridas, de la naturaleza humana. $O$ en otras palabras, si el hombre es malo, si su inclinación es perversa, no hay más que la autoridad para establecer su aprecio por el bien.

Es alli donde radica el aprecio que Schmitt ha hecho notar en De Maistre por la soberanía. Porque la idea del soberano en la tierra no es más que una derivación o floración de la del Soberano por excelencia. Y el soberano tiene por rasgo el gobierno, no le debe nada a la sociedad, del mismo modo que Dios no le debe teoló. gicamente nada a su creación.

18 Sobre la..., De Rivarol, 522. 
Así como ni un gramo de gracia justifica a Dios porque es él que justifica a los hombres, el que da o trasmite la Gracia, así el soberano terrestre no debe nada a los hombres individuales cuyo apetito considerado en sí mismo destruirá la posibilidad de sociedad. De allí la rapidez con que De Maistre establece sus premisas fundamentales: "No puede haber sociedad humana sin gobierno, ni gobierno sin soberanía, ni soberanía sin infalibilidad...".19 "Siendo -dice más adelante-, pues, el hombre necesariamente social, y en el mismo hecho debiendo necesariamente ser gobernado, no depende de su voluntad el establecimiento de un Gobierno... sino que el Gobierno o soberanía es el que resulta directamente de la naturaleza humana".20

De Maistre no sólo dice que su origen es sagrado, ${ }^{21}$ sino que además es infalible y admite excepciones sólo por su propia condición de soberano, es éste el tema que además de llevarle a escribir su "Estudio sobre la soberanía" es esencial para entender su defensa del primado pontificio en "El Papa".

\section{Naturaleza del Orden Politico}

Para estos autores el orden político pende de una relación que emerge de la mutua relación de la creación. La naturaleza del orden político es anterior al hombre, y tiene por ende una consistencia propia que el gobernante debe saber reconocer según los principios del cristianismo, única fórmula, según se reitera, de civilizar al hombre.

Pero hay, evidentemente, una forma de adelantar esa labor y es, justamente, el reconocimiento y sometimiento a esa sabiduría de raíz sobrenatural. En efecto, para la teoría del conocimiento elaborada por De Maistre y De Bonald existen "ideas innatas" (idées innées) o "naturales" (naturelles) que provienen de un estado anterior de plena conciencia, asociado a la plenitud sobrenatural previa al pecado original.

Ellas muestran que el individuo no ha creado nada y que "la parole est -dice De Bonald- l'expression de l'homme moral". "Ce fait absolument primitif et â priori puisqu'on ne saurait remonter avec l'homme et avec la société..,"? La sociedad, en otras palabras,

19 Del Papa, 175.

20 Del Papa, 186.

21 Del Papa, 194.195.

2 Oeuvres de M. de Bonald. Recherches philosophiques.. „, p. 41. 
hace al hombre moral, hace su civilización y muestra la impotencia de la individualidad.

La importancia de esas ideas es inmensa para la construcción teórica de estos autores. Porque ellos deducen que ese lenguaje es parte de un legado suprahumano que constituye o vertebra la tradición de las sociedades. De allí que al defender su tesis filosófica De Bonald recuerde que la posición platónica - en la que se basa en cierto modo- "aussi est éminenment réligieux" y que como tal es no sólo más simple y absoluto que el aristotelismo, sino también "plus ami de choses morales" al contrario del primero, amigo de las cuestiones físicas. ${ }^{23}$

El orden de la Creación es, asimismo, múltiple y vario, y desde sus diversas escalas del ser va preanunciando la heterogeneidad de sus elementos. La homogeneidad, dirá De Rivarol, "es tan absurda en la naturaleza, como la igualdad absoluta entre los hombres y se opone tanto como ésta a la armonía del mundo".24

Los autores defienden el precontractualismo de la sociedad aportando numerosos datos históricos y tesis de corte antropológico para demostrar no sólo la sociabilidad natural de la persona, sino también la connaturalidad de la propiedad en la sociedad, concebida como proyección del patrimonio de las familias.

El hombre vive en sociedad. Es decir, vive en conjunto, se desarrolla condicionado por la historia, las costumbres, por sus mismos congéneres y por la existencia de normas que derivan del orden creado. Es todo lo contrario del salvaje primigenio anunciado por Rousseau. No sólo porque nace entre otros, con millares de las que el escritor ginebrino considera ataduras, sino porque el desarrollo de ellas, incluidas la Cultura y la Religión, constituyen el signo de su elevamiento progresivo y no de su depravación como anunció Rousseau en su Discurso sobre las Artes y las Ciencias.

El hombre que vive en la sociedad, sostienen, es alguien que ha nacido necesitando de los demás; que tiene una historia personal y común; que recibe sus primeras instrucciones de la sociedad; y que recibe de ésta su protección. Existencia que se rige por normas e ideas que son más altas que el individuo; y cuyo adelanto ha recibido en su primera estada en el Paraíso, a través de un entendimiento preternatural cuyos rastros malheridos, están en el lenguaje. "El hombre de la naturaleza, por último, no es el hombre soli-

23 Oeuvres de..., De Bonald, 23.

24 Sobre la..., De Rivarol, 480. 
tario, sino el hombre social...".25 "En la sociedad política constituida -enfatizará De Bonald-... hay hombres sociales, hay comportamientos públicos o sociales. ...26

Si la sociedad existe, por ende, no es por voluntad del hombre aislado, sino por un impulso irresistible del género humano, inscrito en su naturaleza. En ello la voluntad y la inteligencia no han obrado más que para caracterizar las formas singulares de ésa existencia social y por ende de sus costumbres e instituciones políticas.

Todo ello es palpable en la formación del niño.

Para De Bonaid, su ejemplo está en la "educación social" que no es sino la aplicación de sus tesis que el "hombre no existe sino para la sociedad, y la sociedad no lo forma sino para ella: debe, por lo tanto, el hombre emplear al servicio de la sociedad todo lo que ha recibido de la naturaleza y todo lo que ha recibido de la sociedad, todo lo que es y todo lo que tiene".?

La educación, recuerda De Rivarol, es una transacción entre la resistencia y la condescendencia de la persona, y a la cual concurren la religión, la moral y las leyes en distintos grados. "En una palabra, el hombre nace voluntario y animal de costumbres: el gobierno lo protege, la necesidad lo doblega, el mundo lo dirige, la moral lo amonesta y la religión lo convierte".28

\section{LA NACION}

Principalmente es De Maistre quien va a darle otro sentido a la idea de nación frente al uso producido por la Revolución Francesa. Para él, la nación será la continuidad material y espiritual del "alma colectiva", de la "unidad moral" e incluso de eso que llega a denominar la "sabiduría nacional" que se asienta en la lengua, en

25 Sobre la..., De Rivarol, p. 539. A propósito de este tema es preciso destacar que De Maistre sugiere que en el origen de las naciones se encuentra el lenguaje, ver Estudio sobre..., De Maistre, 35.

26 Teoría del poder politico y religioso, De Bonald, 35 .

27 Teoría del..., De Bonald, 4.

28 Sobre la..., De Rivarol, 539. En este mismo sentido escribió en el Diario Politico Nacional que la Asamblea no había querido recordar "que el cuerpo político es una entidad artificial que nada debe a la naturaleza; que los hombres nacen desiguales, y que la ley es el arte de nivelar las desigualdades naturales", De Rivarol, en Escritos..., 95. 
la historia y en el asentimiento social y que se mueve por un misterioso y poderosísimo soplo divino.

Las naciones son, además, singulares, contrapuestas a la ciudadanía universal del Hombre y del Ciudadano de la declaración de derechos. Como tales, las naciones son parte de un plan sobrenatural, cuya finalidad la conoce el Creador. Plan que De Maistre expone al principio de sus Considérations cuando expresa que "Chaque nation, comme chaque individu, a recu une mission qu'elle doit remplir. La France exerce sur l'Europe une véritable magistrature qu'il serait inutil de contester...".29

Estas palabras fueron permanentemente recordadas como se puede ver años después en las ideas que expone en Del Papa y donde numerosas veces se cita asimismo por su obra Considérations sur France. Yo - expresa- "he procurado explicar la (misión) de la Francia, que me parece tan clara y visible como el sol"30 y que sintetiza en el norte que debe tener la alianza de la nobleza con el sacerdocio para recuperar su talante nacional.

En este contexto se entiende que "la nación no puede estar sujeta a convención alguna y menos a una transformación real de manos de los hombres", limitándose sus miembros a ser actores inadvertidos de los designios superiores. ${ }^{31}$

Por lo demás, el patriotismo viene a ser, como dice en sus Considérations, la única realidad del mundo, que distingue franceses, ingleses o españoles, e incluso persas agrega con ironía, pero no el ciudadano universal de la Ilustración. Si es así, si sólo existen estos hombres particulares, existe también una sabiduría, una razón, una abnegación, un carácter general de las instituciones, nacional. Uno francés, inglés, italiano o portugués, o cual proceda.

\section{La tradición, constitución histórica}

"Los jóvenes están lejos de advertir que en política sólo es legítimo lo que es estable". 32 Con estas palabras De Rivarol inició una larga disquisición acerca de la importancia de la estabilidad en la vida política.

29 Considérations..., De Maistre, 2

30 Del Papa, De Maistre, 30.

31 De Maistre y la revolución francesa, Garay Vera, en revista "Academia", n. 18, 59.

32 Sobre la..., De Rivarol, 519. 
Esa disquisición del autor citado refrenda la concepción que el gobierno sea un campo de confrontación de opiniones, ideas o planes; lo que hay —-sostiene- en el campo de la política es Ia viabilidad o no de los proyectos concretos.

La política no es más que la historia o esta misma no es sino política experimental según el precepto de De Maistre. "Ouvrons Thistoire qui est la politique expérimentale". 33 Los pueblos no viven de demostraciones sino de verdades sociales, de principios firmemente asentados, anteriores a los integrantes de la sociedad y custodiados por la autoridad. Principios que tienen el carácter indemostrable de los primeros principios, tal como en la geometría los axiomas - recalca De Maistre- son incuestionables y ajenos a toda comprobación.

Esas verdades sociales son los juicios o prejuicios, cuya bondad o maldad se califica según si son estables o precarios. Para la vida del pueblo, da lo mismo que sean leyes o costumbres, por que lo principal es que la autoridad cumpla con eficacia sus planes.

El talento político, añade De Rivarol, consiste en acercarse a la tradición, a ese conjunto de juicios o prejuicios: "El genio, en política, consiste, no en crear, sino en conservar; no en cambiar, sino en estabilizar; consiste, en fin, en suplir las verdades con normas; pues no es la mejor ley, sino la más estable, la que es buena". ${ }^{34}$

Pero para los autores ese orden estable, plenamente natural en el sentido de ajustado a la creación divina, tiene sus dos grandes hitos en la Creación y en la Caída. Y si se ignoran ambos, agregan, se olvida la naturaleza humana, el mal, y la lucha del bien en la tierra. "Hoy en día -dirá Blanc du Saint-Bonnet- dos nociones se nos escapan cada vez más, la de la creación y la de la caída. La primera desaparece de la razón, y la segunda de la experiencia misma". 35

33 Essai sur le principe générateur des constitutions, De Maistre, 190, en Considérations... Sobre esta idea el autor vuelve numerosas veces, lo que se nota por ejemplo en el género de sus discusiones. Cuando discute acerca de la posibilidad de la vuelta del Rey a Francia, propone entre otras la posibilidad de "interrogé l'histoire" y más adelante pide "en ne perdant jamais de vue l'histoire et la nature de l'homme", Considérations..., p. 99. Cuando examina las constituciones aplica este método otras muchas veces por ejemplo en sus considerandos IV y VII de su Essai...

34 Sobre la..., De Rivarol, 519.

35 Politica..., Blanc du Saint-Bonnet, 19. 
Sin embargo, esta defensa radical de la tradición llevaría a sus autores a una paradoja notoria: la de propugnar en su filiación divina una esencia ahistórica a la tradición. Porque tradición fue tanto para De Maistre como para De Bonald un reflejo, al igual que el lenguaje, del orden anterior a la Caída, y por ende la expresión de un orden armónico y perfecto, de impronta angélica. Un orden, cuya sustancia histórica estaba en los hechos relegada por esta primacía teológica ${ }^{36}$ a la cual vuelve cada vez que se establece el estado de gracia.

\subsection{La filosofía como falsa constitución}

No son pocas las páginas deđicadas por estos autores a denunciar los principios revolucionarios. Ellos son los que a su juicio han atraído sobre las sociedades la innovación y la diversidad de opiniones, atrayendo la ruina del Estado.

"Todo filósofo constituyente está preñado de un jacobino: es una verdad que Europa no debe perder de vista". Bajo esta acepción De Rivarol añadió que las verdaderas luces se difundían no por las teorías, sino por los logros siendo la "naturaleza de las cosas" la que se oponía al triunfo de las aspiraciones ilustradas. ${ }^{37}$ "Así pues, se entiende actualmente por filósofo, no el hombre que enseña el gran arte de dominar las pasiones o de aumentar las luces propias, sino aquel que asocia al espíritu de independencia, el despotismo de sus decisiones; que duda de todo lo que existe, y afirma todo lo que dice; el hombre, en fin, que sacude prejuicios sin adquirir virtudes".38

Con estas palabras De Rivarol sintetizó el juicio respecto de la "secta" que, avasallante, imponía sus nuevas ideas. Un filósofo, es, como dirá De Rivarol, un hombre que ignora las proporciones, las relaciones y las jerarquías de los seres, y que se empeña en re-

36 Palacios subraya que para De Bonald "el hombre es un ser enseñado, instruido por Dios desde su origen mismo, y que no ha llegado de hecho al conocimiento de las verdades generales, morales y sociales por medio de una lenta evolución, sino de golpe y por revelación divina, nada más salir de las manos de su Creador. Y $\mathrm{Y}$ estas verdades, fundamento del orden social, tienen a Dios por autor, como el orden social mismo", El platonismo..., 26.

37 Sobre la..., De Rivarol, 513.

38 Sobre la..., De Rivarol, 510; ver similares críticas en Teoria del Poder..., De Bonald, 141 y en Estudio sobre..., De Maistre, 14. 
producir un sistema igualitario desprovisto de vitalidad, porque el método del analista es la observación. ${ }^{39}$

El filósofo como ilustrado rechaza la singularidad, lo histórico y la desigualdad. Es un profeta de un mundo ideal y homogéneo. Su afán idealizador le hace desconfiar de la costumbre y sobrevalorar el valor de la ley: para él, sin ley parece casi imposible preservar la sociedad.40

La filosofía es una escuela de pensamiento, lo suficientemente audaz para desafiar la tradición de una nación y proponer en su reemplazo dogmas civiles basados en la libre opinión. Pero esa filosofía no recoge los fundamentos sobrenaturales ni históricos $y$, por ende, contraría las condiciones básicas de la perdurabilidad del orden político.

Cuando De Maistre ataca a Thomas Payne, porque éste ha dicho que no hay constitución en un país hasta què se la puede meter en un bolsillo, ése es el instante fundamental de la cuestión que atañe al orden jurídico para los autores estudiados.

En efecto, porque De Maistre no se cansa de repetir en su Essai sur le principe générateur des constitutions que las leyes fundamentales de una sociedad no están escritas y que la constitución de un país está dada por su historia, sus leyes y sus costumbres.

Por ello distingue tres puntos fundamentales respecto de la Constitución escrita:

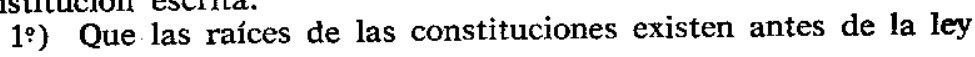
escrita;

2:) Que una ley constitucional no puede ser más que el desarrollo o la sanción de "droit préexistant et non écrit"; y

3:) Que lo verdaderamente esencial, lo más intrínsecamente institucional "n'est jamais écrit, et même ne saurait l'être, sans exposer l'Etat". 41

Siendo más de treinta los considerandos de su ensayo es posible sin embargo hacer una breve revisión de sus argumentos. En primer lugar, De Maistre atiende al hecho que por donde se mire que haya una constitución hay antecedentes, costumbres y normas. EI caso de Inglaterra que verdaderamente le apasiona le demuestra además que la constitución no es conocida, que existe un Consejo Privado al que se deja hacer y que no son las leyes las que terminan su vitalidad.

39 Sobre la..., De Rivarol, 510.

* Teoría del..., De Bonald, 84.

41 Essai..., De Maistre, en p. 173 en "Considérations...", 173. 
Lo que determina su vitalidad, dice, la "véritable constitution anglaise est cet ésprit publique, admirable, unique, infaillible, audessus de tout éloges qui mene tout, qui conserve tout, qui sauve tout". ${ }^{42}$ Por el contrario, eso que está escrito, eso precisamente es nada, como lo resalta continuamente.

La Constitución de los filósofos es, en definitiva, una construcción teorica que no puede dar cuenta de las verdaderas leyes fundamentales de una sociedad, ni tampoco de las circunstancias de la sociedad, destruyendo su importancia a medida que -como De Maistre advierte - se multiplica el número de sus artículos. ${ }^{43}$

De allí que De Maistre sentencie que uno de los grandes errores del siglo "fut de croire qu'une constitution politique pouvait être écrite, et crée a priori, tandis que la raison et l'expérience se réunissent pour établir qu'une constitution est une oeuvre divine, et que ce qu'il y a précisément de plus constitutionnel dans les lois d'une nation ne saurait être écrit".44

\section{Retigión, moral y ley}

\subsection{Religión}

Los autores expuestos debatieron largamente el papel de la religión en la monarquía por ellos defendida. En efecto, la permanencia de los valores cristianos fue vista como la única garantía por los mismos para preservar la sociedad.

El libre examen, adujeron, favorecería la disgregación de las opiniones y las ideas, permitiendo la relajación de las normas que sujetaban la sociedad. De allí el valor fundamental que adquiere para ellos la religión, porque además de valorarse en cuanto preocupación salvífica trasmundana, se destaca en cuanto proveedora de las nociones de bien y mal fundamentales. "En una palabra, la filosofía divide a los hombres por las opiniones; la religión los une en unos mismos principios: hay por ende un contrato eterno entre la política y la religión. Todo Estado es, si oso decirlo, un navio misterioso que tiene sus anclas en el cieto".45

42 Essai..., De Maistre, 171; en el cap. IX distingue, en la nota 2 que habla de la constitución natural, "car sa constitútion écrite n'est que du papier", 105.

13 Essai..., 173.

4 Essai..., 167.

45 También De Rivarol agrega que la "religión es la que hace 
La religión, desde este punto de vista, ilumina los contenidos de la ley, y al mismo tiempo le completa en su acción persiguiendo, como ya se ha dicho, los crímenes ocultos a la luz de la autoridad y de los hechos. "El orden social - añade De Rivarol- perecería, si el gobierno dejase impunes los delitos constatados; y los crímenes cometidos en la sombra le escaparían y acabarían por trastornarlo todo, sin el apoyo de la moral y el freno de la religión, que son así los principales suplementos de la justicia humana".46

"Los crímenes - dirá a su vez Blanc du Saint-Bonnet- están siempre ahí, el estado no puede cambiar los códigos ni retirar sus leyes. La Caída continúa, puesto que Dios continúa levantándonos...".47

Para tener ese valor De Rivarol argumentó que los principios de la Religión eran misteriosos y debían mantener su condición de indemostrabilidad, porque lo propio de una religión es no ser demostrada, por lo que una religión demostrada sería lo mismo que la física o la geometría demostrada, es decir un problema no religioso. ${ }^{48}$

Refiriéndose al valor político de la religión, los autores manifestaron su acuerdo respecto a su utilidad política. Todos le señalaron como indispensable para el orden político y De Maistre llegó a exponer su tesis de la "religión de Estado" dentro de la política de Estado, de modo de configurar un conjunto de "dogmas políticos y religiosos" para frenar las aberraciones de la razón individual. Tesis que es la que está en la base de su idea de la Iglesia Galicana como expresión feliz tanto del primado francés del catolicismo como del genio nacional.49

De Rivarol, por su parte, afirmó que aun en su versión peor concebida sería siempre más beneficiosa para el orden político, en-

que la multitud sea fiel a ciertas ideas", Sobre la..., 527. De Maistre dice en una nota: "Que nulle institution quelconque ne peut durer, si elle n'est fondée sur la religion", Essai..., en Considérations..., 189.

46 Sobre la..., De Rivarol, 522.

47 Politica..., Blanc du Saint-Bonnet, 30.

48 "No se trata de saber si una religión es verdadera o falsa, sino de si es necesaria... si determinada religión no ha sido demostrada, y no obstante se ha demostrado que es necesaria, dicha religión posee una verdad política", Sobre la..., De Rivarol, 531.

49 Estudio sobre..., De Maistre, 59, asunto tratado en el capítulo $\mathrm{X}$ del libro citado, titulado "Del alma nacional". 
tre otras cosas porque la piedad facilita la obediencia de los súbditos: "la religión -agrega- hace fácil el ejercicio del poder".50

Obediencia que se haría más fuerte y perdurable porque a su juicio mientras la filosofía actúa sobre la inteligencia, la religión se sustenta sobre un sentimiento más universal que es la emoción, móvil directo de la conducta humana.

Fue, en definitiva, el mismo principio que destacó De Bonald, cuando afirmó que la religión era "sentimiento, y no opinión" y que en esa calidad impulsaba a la unidad de la sociedad.51

El rechazo del racionalismo como criterio fundamental de la existencia humąna tiene pues un sentido mucho más profundo que el antirracionalismo, a la luz de la antropología que estos autores manejan. Sobre todo por la restricción que al racionalismo, como razón "individual", le anexan en virtud de las necesidades sociales.

Sobre esta base revalorizarán el papel de la religión en el orden político y sobre todo darán nuevas bases a la acción del Estado. En su concepción si la Religión proporciona una base más confiable para el orden político, es deber del Estado, recíprocamente, satisfacer las necesidades de la religión. 52

La religión tiene, pues, un papel relevante en esta nueva Monarquía, sobre todo porque ella recogería la observación de De Maistre, que mientras más fuerte fuese la influencia religiosa en su constitución política natural, mayor sería su longevidad y estabilidad. ${ }^{53}$

\subsection{Moral}

Sostiene De Rivarol que así como todo conspira a favor del orden físico - la gravedad, el peso de los cuerpos, etc.- también debe atenerse la sociedad a ofrecer todo para la conspiración "en el orden moral a favor de la virtud contra el vicio". Conspiración que te-

so Sobre la..., De Rivarol, 526.

51 Teoría del..., De Bonald, 102. Sobre este mismo asunto De Rivarol sostiene: "Hay en el corazón del hombre, una fibra religiosa que nada puede extirpar, y que siempre excitarán la esperanza y el temor. La cosa es, entonces, dar al hombre temores y esperanzas definidas", Sobre la..., 518.

52 De Bonald argumentó que la religión auxiliaba al poder político porque reprimía la intensidad de los conflictos de los hombres, ver Teoría del..., 141.

53 Essai..., De Maistre, en Considérations..., 191. 
niendo por socios la religión y la política, lograría introducir en el orden moral la inclinación de la naturaleza. ${ }^{54}$

El orden moral depende por cierto de las premisas desarrolladas por el catolicismo. Sin ese sentido religioso superior la "moral sin religión, es la justicia sin tribunales: moral y religión, justicia y tribunales, son todas cosas correlativas, y cuya existencia es solidaria como la palabra y el pensamiento".55

\subsection{Ley}

La ley viene a ser así una expresión precaria respecto de la perfección creada del orden físico, por cuanto al suponer el oscurecimiento de la inteligencia después del pecado original del individuo importa también la trasgresión continua del orden moral.

Desarrollando De Maistre esta idea, como corolario de su idea en cuya virtud mientras más perfecta era una institución, menos escritas aparecían sus leyes que "n'a rien écrit du tout en s'établissant, pour nous faire sentir que toute loi écrite n'est qu'un mal nécessaire, produit par l'infirmité ou par la malice humaine; et qu'elle rien du tout, si elle n'a recu une sanction antérieure et non écrite".56

Consecuentemente a esta precariedad de la ley con respecto del orden natural se entiende la distancia que frente a ella van tomando. Porque primero la ley, como se la viene a definir con posterioridad, pasa a ser una decisión de voluntades, de la múltitud, y de ella -dice De Maistre- no pueden salir más que leyes mudables, pero no leyes fundamentales que tampoco las podría crear si quisiese.

La ley civil, como la llama De Bonald, es la fijación de las relaciones entre los ciudadanos, que es derivación de la "naturaleza de las profesiones y de la naturaleza de las propiedades".57

De acuerdo a esa sola enunciación la ley positiva, para distinguirla de la ley natural, existe en compensación al desequilibrio moral de la existencia humana. La ley, agregará De Bonald, "indica a la sociedad el vicio de una ley defectuosa o incompleta por el carácter de los desórdenes de los cuales ella está agitada...".58

54 Sobre la..., De Rivarol, 523.

55 Sobre la..., 527.

s6 Essai..., De Maistre, en Considérations..., 183.

57 Teoría del..., De Bonald, 82 ss.

58 Teoria del..., De Bonald, 82. 
Segundo, porque la ley existe para remediar la falencia producida por el mal uso de la libertad, pero incluso su aplicación no es lo suficientemente exhaustiva del trasgresor, Io que implica su relativa ineficacia: quedará siempre como recurso último el juicio de Dios, que juzga en la conciencia, más allá de la escrutación de autoridades y jueces.

Por ello la ley tendrá un valor relativo ante estos autores. Ciertamente las costumbres, como expresiones de la tradición, fueron mejor consideradas que las leyes, acusadas a veces de ser innovaciones cuya bondad sólo probará el tiempo. Es conveniente recordar las anteriores expresiones de De Rivarol sobre que la bondad de las leyes reside en su estabilidad o permanencia. Esta "es la razón - afirma- de que las costumbres suplan perfectamente a las leyes", por lo mismo concluye que "una ley conocida y probada vale más que una ley nueva que parece mejor". 59

Todo esto tiene importante repercusión sobre la materia constitucional. Porque una constitución natural es, para De Maistre, la expresión de un orden divino, que los hombres sólo podrán reconocer pero no sustituir. Una constitución no existirá más que como un conjunto de costumbres y de leyes morales, cuya excepción dará origen a la ley. Una constitución será, en su definición, "ouvrage des circonstances, et le nombre de ces circonstances est infini". ${ }_{00}$ En consecuencia, nunca podrá dar cuenta de los elementos más fundamentales si la escribe. "L'homme ne peut faire une constitution, et nulle constitution légitime ne saurait être écrite. Jamais on n'a écrit, jamais on n'écrira a priori le recueil des lois fondamentales qui doivent constituer una société civile ou réligieuse".61

Por lo demás, el propio De Bonald afirmará que el origen de la ley suele ser la costumbre, lo que supone su superioridad sobre la primera: "En Francia, todas nuestras leyes políticas no eran más que costumbres a las que no se podía asignar la época, ni fijar el origen".62

Esa constitución natural obedece, obviamente, a criterios diver-

59 Sobre la..., De Rivarol, 519. Casi en el mismo sentido Blanc du Saint-Bonnet afirmó que las "costumbres deciden sobre las leyes, 57.
60 Essai..., De Maistre, en Considérations..., 175.
61 Essai..., 189.
62 Teoria del..., De Bonald, 82. 
sos a los expuestos por los propagandistas de las declaraciones de derechos, porque las leyes, en tanto se escriben, no recuerdan o consagran realidades evidentes ya que tienen su origen inmediato en la lucha de los partidos o facciones, y no en una creación política propiamente tal, capacidad que escapa al hombre. ${ }^{63}$

\section{LA MONARQUIA CONSAGRADA}

Reflexionando acerca de la naturaleza de su ideal político, De Maistre añadió una distinción bastante original respecto de las acusaciones vertidas sobre la monarquía. En efecto, el saboyano sostuvo que lo único verdaderamente reprobable a la tradición occidental era el despotismo oriental. "Lo que verdaderamente nos disgusta, lo que no concuerda de ninguna manera con nuestro carácter ni con nuestras antiguas costumbres, indiscutibles, es el gobierno ministerial o visiriato. La inmovilidad oriental se adapta muy bien a este gobierno y rehúsa incluso cualquier otro, pero la raza audaz de Jafet, de ningún modo lo quiere, porque en efecto esta forma no le conviene para nada". ${ }^{64}$

Esta distinción no es por lo demás una referencia aislada en su obra. Se la encuentra algo más desarrollada en El Papa cuando acude a una serie de distinciones de carácter cultural y espiritual que conviene resaltar. Porque la política presenta para él dos grandes modelos. La raza "audaz" o "atrevida", según otra traducción, de Jafet y la raza de Sem y Cam.

La primera tiende a buscar la libertad, a hacer del gobierno lo menos gobierno posible. El europeo, dice De Maistre, identificándolo con la raza de Jafet, lo ha ensayado todo frente al soberano. Por el contrario, la raza de Cam y Sem, los pueblos orientales, tiende a la inmovilidad, a la pasividad frente al gobernante.

De Maistre en este dilema opta ciertamente por la raza de Jafet, porque "nada hay tan insoportable a nuestro orgullo que el gobierno

63 Estudio sobre..., De Maistre, 57.

64 Estudio sobre..., 118. Algo más adelante matiza su juicio, advirtiendo que bajo el poder de los califas, déspotas orientales, se vivió un tiempo de esplendor, ver p. 186. Sobre este punto De Bonald consideró que el despotismo era el poder particular de un hombre y que se desplega en su integridad en las guerras, Teoría del..., 24. 
despótico",65 mas ello no resuelve la cuestión de cuánto puede sufrir un gobierno sin perder su soberanía.

De modo que esta breve incursión sobre el despotismo viene a confirmar que lo despótico no es la ausencia de constitución escrita como pretendían los revolucionarios -y a quienes indirectamente contesta - sino aquello que no estando en el legado de la naturaleza atenta al orden divino.

Aquí se entrelazan, pues, tres géneros de argumentos. En primer lugar, el histórico, que muestra que lo constitucional no corresponde a lo escrito, y por ende, lo escrito no puede garantizar la existencia de una nación ni los derechos de sus miembros. La nación, de acuerdo a este argumento, existía antes de la escritura de los derechos, antes de la Constitución, por lo que se prueba que la carencia de ellos no puede implicar el despotismo.

El segundo argumento es de carácter metafísico. Lo contrario de un buen gobierno es justamente gobernar como si no existiera una naturaleza creada. Y el hombre, el súbdito, tiene en esa precisa condición una suerte de fuero. Por tanto lo despótico es ignorar metafísicamente hablando la precedencia ontológica de la creación divina, y politicamente la violación de la naturaleza humana.66

En ese primer sentido Antoine Blanc du Saint Bonnet había escrito en una nota agregada a su texto principal de "Política real": "E1 despotismo no es más que la sustitución de la voluntad humana a la voluntad de Dios: cuando el Soberano, por ejemplo, sustituye su voluntad a la justicia".67

EI tercer argumento es cultural. Lo inaceptable es pues Ia similitud con Oriente, el "despotismo oriental" de los antiguos, que se identifica sucesivamente con las monarquías asirias y babilónicas, y luego con las monarquías helenísticas.

De Maistre quería, lo mismo que De Bonald, Blanc du Saint Bonnet y De Rivarol, una monarquía "divinizada"' que, identificada

65 Del Papa, De Maistre, 188-189.

6 De Rivarol es el único de ellos que defiende la posibilidad de deponer a un rey por gobernar despóticamente, que son "errores suficientemente graves como para que los tronos resulten derribados por ellos: pues todo va en proporción", Sobre la..., De Rivarol, 523. De Maistre Ilega a atribuir al protestantismo la justificación del derecho de rebelión, negando de hecho la doctrina establecida por los teólogos-juristas españoles del siglo XVI y las palabras del propio Santo Tomás de Aquino, ver Del Papa, 191.

67 Política..., Blanc du Saint-Bonnet, 21-22. 
con la religión, aprovechare su inmensa fuerza política y que al mismo tiempo le sirviera como monarquía dilecta de la Cristiandad.

Con ello se daba cumplimiento a aquello que De Maistre había identificado como una de las constantes de la monarquía nacional francesa, es decir su carácter religioso. El modelo de la monarquía consagrada era, pues, el que se escondía en esta reflexión. "Un caractère particulier de cette monarchie, c'est qu'elle possede un certain élément théocratique qui lui est particulier, et qui lui a donné quatorze cents ans de durée: il n'y a rien de si national que cet élément. Les évêques, succeseurs des druides sous ce rapport, n'ont fait que le perfectionner". 68

Es preciso, pues, considerar que en esa supuesta reconstrucción monárquica su opinión del papel del constitucionalismo venía considerablemente deprimido, a consecuencias de identificarlo con la plenitud del sistema revolucionario que, a sus ojos, no era más que la perversión del orden divino. Es en este sentido que hay que entender las condenaciones que lanza De Maistre en contra del alarde constitucionalista, cuando expresa que muestra "la profonde imbécillité (...), la profonde imbécillité, dis-je, de ces pauvres gens qui s'imaginent que les legislateur sont des hommes, que les lois son du papier, et qu'on peut constituer les nations avec de l'encre. Elles montrent au contraire que l'écriture est constamment un signe de faiblesse, d'ignorance ou de danger...".69

\section{BIBLIOGRAFIA}

Antoine Blanc du Saint-Bonnet, Politica real. Iction, Buenos Aires, 1980.

Louis-Ambroise de Bonald, Teoría del poder politico y religioso (1796). Tecnos. Madrid. 1988.

Louis-Ambroise de Bonald, Teoría de la Educación Social en "Teoría del poder político y religioso", Tecnos. Madrid. 1988.

68 Essai..., De Maistre, en Considérations..., 189. Estas ideas son ahondadas y expuestas en similar forma en El Papa, 30-31 especialmente cuando dice "En el gobierno natural y en las ideas nacionales del pueblo francés se encuentra por todas partes un no sé qué elemento teocrático y religioso", p. 30.

69 Essai..., De Maistre, en Considérations..., 183. 
Louis-Ambroise de Bonald, Oeuvres de $M$. de Bonald. Recherches philosophiques sur les premiers objects des conaissances mo rales. Démonstrations philosophique de principe constitutif de la société. Meditations politiques tirées de I'Evangile. Libr. d'Adrien le Clerc. París. 1853.

Joseph de Maistre, Consideraciones sobre Francia. Fragmentos sobre Francia. Ensayo sobre el principio generador de las constituciones políticas, Ediciones Dictio. Buenos Aires. 1980.

Joseph de Maistre, Considérations sur la France suivies de l'Essai sur le principe générateur des constitucions politiques, Bruxelles, 1852.

Joseph de Maistre, Estudio sobre la soberania, Ediciones Dictio, Buenos Aires: 1978.

Joseph de Maistre, Del Papa, y de la Iglesia galicana en sus relaciones con la Santa Sede. Madrid. 1856.

Joseph de Maistre, De l'Eglise gallicane dans son rapport avec le Souverain Pontife. Pour servir de suite à l'ouvrage intitulé Du Pape. Lyon. 1874.

Joseph de Maistre, Examen de la philosophie de Bacon, ou l'on traité différents questions de philosophie rationnelle (10 ème, ed.). Paris. 1874. 2 vols.

Joseph de Maistre, Las veladas de San Petersburgo. O coloquios sobre el gobierno temporal de la Providencia, Apostolado de la Providencia. Madrid. 1922.

Antoine de Rivarol, Escritos politicos 1789-1800, Ediciones Dictio. Buenos Aires. 1980.

\section{FUENTES SECUNDARIAS}

Ernst Benz, Les sources mystiques de la phitosophie romantique allemande, Librairie J. Vrin. Paris. 1968.

Marcel de Corte, La filosofía politica de Bonald, en Arbor (Madrid), № 20 (1951), 191-211 y 348-368.

William Harbour, El pensamiento conservador, Grupo Editor Latinoamericano. Buenos Aires. 1985.

Cristián Garay Vera, De Maistre y la Revolución Francesa, en Academia (Santiago de Chile), No 18 (1989), 51-65.

John Scott Mc Clelland, comp., La derecha francesa. (De Maistre a Maurras), Extemporáneos. México. 1975. 
Leopoldo-Eulogio Palacios, Estudios sobre Bonald, Editorial Speiro. Madrid. 1987.

Leopoldo-Eulogio Palacios, El platonismo empírico de Luis de Bonald, en Revista de Estudios Políticos (Madrid), N: 74 (1954), 3-27.

John Weiss, Conservantism in Europe 1770-1945: Traditionalism, reaction and counter-revolution, Harcourt Brace Jovanovich. Norwich. 1977.

Auguste Viatte, Les sources occultes du romantisme, illuminismethéosophie 1770-1820, Librairie Honoré Champion (2 vols.). 1969. 